\title{
SALIVARY FLOW RATES AND IODIDE TRAPPING CAPACITY IN PATIENTS WITH SJÖGREN'S SYNDROME
}

\author{
BY
D. K. MASON, R. McG. HARDEN, J. A. BOYLE, M. K. JASANI, J. WILLIAMSON, AND W. W. BUCHANAN
University Department of Medicine, Western Infirmary, the Centre for Rheumatic Diseases, and University Department of Medicine, Royal Infirmary, Glasgow

Sjögren's syndrome (Sjögren, 1933) in its severer forms presents a relatively simple clinical diagnosis. In many patients, however, the condition may be mild and it may be difficult for the clinician to find laboratory evidence of, for instance, dryness of the mouth. Biopsy of the salivary glands is not without operative complication and probably has no place in the routine investigation of the patient suspected of having Sjögren's syndrome. Salivary flow studies and sialography frequently confirm salivary gland involvement in severe cases but are often normal in milder cases with complaints of xerostomia (unpublished observations).

In the search for a more specific test of salivary gland involvement, we decided to explore the capacity of the salivary glands to trap iodide in Sjögren's syndrome, because the normal salivary glands share this capacity with the thyroid gland.

In this paper we report the clinical findings, sialographic results, salivary flow rate determinations, and saliva plasma radioiodine ratios in fourteen patients with Sjögren's syndrome. In addition, an attempt has been made to correlate sialographic findings with salivary flow rates. In this study we have used the short-lived isotope ${ }^{132}$ I with its half life of $2 \cdot 26$ hours. The radiation dose which the patient receives from $50 \mu \mathrm{c}$. of this isotope is negligible.

\section{Patients Studied}

\section{Methods}

Three of the fourteen patients with Sjögren's syndrome were male and eleven female; their ages ranged from 53 to 78 years. All complained of xerostomia and had keratoconjunctivitis sicca. The latter was confirmed by diminished wetting of a filter paper strip during a 5minute Schirmer test for tear secretion after inhalation of 10 per cent. ammonia, rose-bengal staining of the conjunctivae, and the finding of filamentary or punctate keratitis on slit-lamp examination (Williamson, Cant,
Mason, Greig, and Boyle, 1967). Four patients had "definite" rheumatoid arthritis (Ropes, Bennett, Cobb, Jacox, and Jessar, 1959).

Only two patients gave a history of salivary gland enlargement. Oral dryness had been present from 1 to 25 years; in ten of the patients it was intermittent and in four persistent. Difficulty with mastication, increased fluid intake, oral soreness, ill-fitting dentures, and cracking of lower lips were common complaints. On oral examination, dryness of the mouth, fissuring of the tongue, and angular cheilosis or cheilitis were noted.

\section{Studies of Salivary Gland Function}

(a) Sialography.-A hydrostatic technique was employed, using sodium metrizoate (Triosil "45") as a contrast medium (Park and Mason, 1966). The contrast medium entered the duct through a tapered polythene catheter from a glass container positioned $70-90 \mathrm{~cm}$. above the patient's head. By this method overfilling of the gland rarely occurred. A film was taken at the completion of the filling phase. As the water soluble contrast medium is rapidly expelled from the gland, a secretory phase film was taken 5 minutes after completion of the filling phase. Between the two phases salivary flow was stimulated with lemon juice. Sialography was performed after the measurements of salivary flow rate and saliva plasma ${ }^{132} 1$ ratios.

(b) Measurement of Salivary Flow Rate.-Parotid saliva was collected using a modified Carlson Crittenden cup (Carlson and Crittenden, 1910) with an internal chamber diameter of $10 \mathrm{~mm}$. and an external chamber diameter of $20 \mathrm{~mm}$., or by cannulation of the parotid ducts as described by Kerr (1961). The saliva was passed via polythene tubing through a drip chamber and each drop recorded using a photo-electric detector system (Mason, Harden, Rowan, and Alexander, 1967). Saliva was collected under "resting" conditions and after fruit gum, lemon juice, and occasionally paraffin wax stimulation. The collections were continued until $1 \mathrm{ml}$. saliva was obtained at each flow rate, but this was not always possible especially under "resting" conditions (Mason, Harden, and Alexander, 1967). 
(c) Measurement of Salivary/Plasma ${ }^{132}$ I Ratio.132I was milked from a ${ }^{132}$ I Tellurium column containing 132I Tellurite absorbed on aluminium hydroxide gel. The column was supplied by the Radiochemical Centre, Amersham. $1 \mathrm{ml}$. of a solution of $\mathrm{N} / 100 \mathrm{NH}_{4} \mathrm{OH}$ was added to 1 litre of normal saline. $10 \mathrm{ml}$. saline were then allowed to run slowly through the column. ${ }^{132}$ Tellurium transmutes to ${ }^{132}$ I by radioactive decay. The 132I which was washed off the column was counted in an ionization chamber against a ${ }^{60}$ Cobalt source.

Fifty $\mu$ c. 132I was administered orally to the fasting patient one hour before the commencement of the collection of saliva. Blood was collected at the mid-point of each salivary collection and the radioactivity of the plasma was assumed to be the mean radioactivity during the collection period (Alexander, Koutras, Crooks, Buchanan, Macdonald, Richmond, and Wayne, 1962). The plasma and salivary ${ }^{132} \mathrm{I}$ (per cent. dose/ml.) were measured in a well-type scintillation counter and the saliva/plasma ${ }^{132} I$ ratio calculated for each flow rate.

\section{Results}

(a) Saliography. - Of the fourteen patients studied, five had normal sialograms (Table, opposite).

The nine abnormal sialograms were classified as punctate, globular, or cavitary (Bloch, Buchanan, Wohl, and Bunim, 1965); in four the sialectasis was punctate (Fig. 1), in two globular, and three cavitary
(Fig. 2). Atrophic changes were found in seven of the nine abnormal sialograms (Table).

\section{(b) Measurement of Salivary Flow}

Normal Range of Salivary Flow.-The mean and standard deviation of measurements of salivary flow rate made in $\mathbf{8 3}$ normal subjects under resting, fruitgum stimulated, and lemon-juice stimulated conditions were $0.059 \pm 0.039,0.36 \pm 0.92$, and $1.70 \pm$ $0.69 \mathrm{ml} . / \mathrm{min}$. respectively. The results of salivary flow measurements are not, however, distributed in a Gaussian fashion; marked skewness to higher values obtains when the data for the normal subjects are plotted as a frequency distribution curve (not shown). Because of this the lower limit of the normal range is not given by the mean minus two standard deviations. We therefore take, in our laboratory, the lowest measurements of salivary flow under resting, fruit-gum stimulated, and lemonjuice stimulated conditions in these 83 normal patients as defining our lower range of normal. These figures are $0.01,0.09$, and 0.50 for the three conditions of salivary flow respectively.

Patients with Sjögren's Syndrome.-The results of measurements of salivary flow rate in the patients with Sjögren's syndrome are shown in the Table.

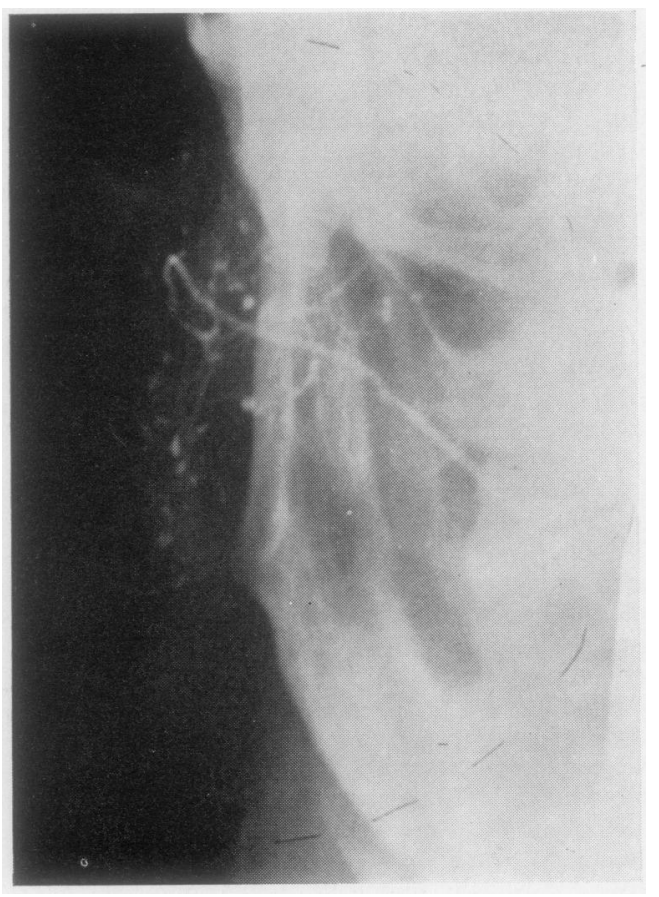

Fig. 1.-Punctate sialectasis.

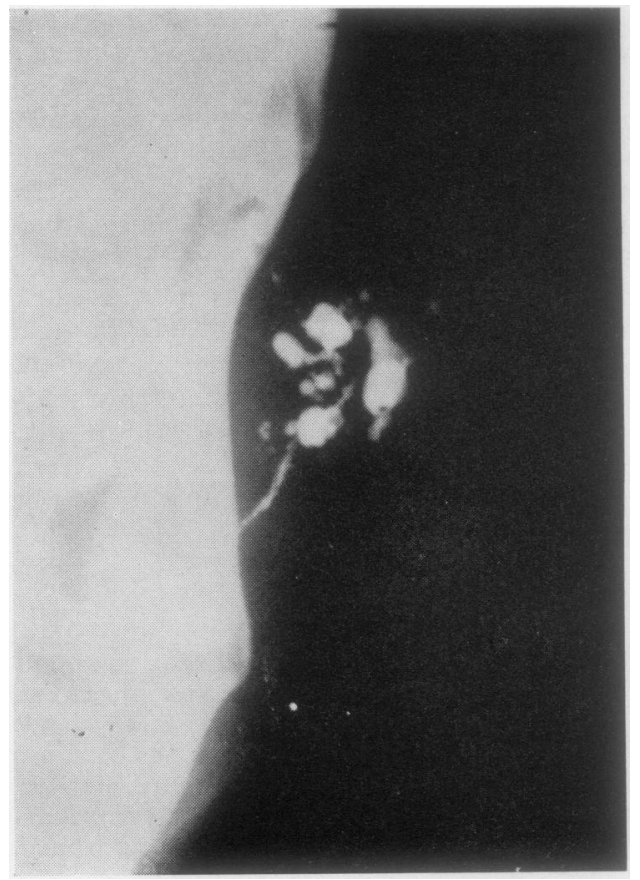

Fig. 2.-Cavitary sialectasis. 
TABLE

SIALOGRAPHIC FINDINGS, FLOW RATE MEASUREMENTS, AND SALIVA/PLASMA ${ }^{132}$ I RATIOS IN THE FOURTEEN PATIENTS STUDIED

\begin{tabular}{|c|c|c|c|c|c|c|c|c|c|c|c|}
\hline \multirow{3}{*}{$\begin{array}{l}\text { Patient } \\
\text { No. }\end{array}$} & \multicolumn{5}{|c|}{ Sialographic Findings } & \multirow{2}{*}{\multicolumn{3}{|c|}{$\begin{array}{c}\text { Flow Rate } \\
\text { Parotid Saliva (ml./min.) }\end{array}$}} & \multirow{2}{*}{\multicolumn{3}{|c|}{ Saliva/Plasma 132I Ratio* }} \\
\hline & \multirow[b]{2}{*}{ Normal } & \multirow[b]{2}{*}{ Atrophied } & \multicolumn{3}{|c|}{ Sialectasis } & & & & & & \\
\hline & & & Punctate & Globular & Cavitary & Resting & $\begin{array}{l}\text { Fruit-Gum } \\
\text { Stimulated }\end{array}$ & $\begin{array}{l}\text { Lemon-Juice } \\
\text { Stimulated }\end{array}$ & Resting & $\begin{array}{l}\text { Fruit-Gum } \\
\text { Stimulated }\end{array}$ & $\begin{array}{l}\text { Lemon-Juice } \\
\text { Stimulated }\end{array}$ \\
\hline $\begin{array}{r}1 \\
2 \\
3 \\
4 \\
5 \\
6 \\
7 \\
8 \\
9 \\
10 \\
11 \\
12 \\
13 \\
14\end{array}$ & $\begin{array}{l}\mathbf{0} \\
\mathbf{0} \\
\mathbf{0} \\
\mathbf{0} \\
\mathbf{0} \\
\mathbf{0} \\
\mathbf{0} \\
\mathbf{0} \\
+ \\
\mathbf{0} \\
+ \\
+ \\
+ \\
+\end{array}$ & $\begin{array}{l}+ \\
+ \\
+ \\
+ \\
0 \\
+ \\
+ \\
+ \\
0 \\
0 \\
0 \\
0 \\
0 \\
0\end{array}$ & $\begin{array}{l}0 \\
+ \\
0 \\
+ \\
+ \\
0 \\
0 \\
0 \\
0 \\
+ \\
0 \\
0 \\
0 \\
0\end{array}$ & $\begin{array}{l}+ \\
\mathbf{0} \\
\mathbf{0} \\
\mathbf{0} \\
\mathbf{0} \\
\mathbf{0} \\
+ \\
\mathbf{0} \\
\mathbf{0} \\
\mathbf{0} \\
\mathbf{0} \\
\mathbf{0} \\
\mathbf{0} \\
\mathbf{0}\end{array}$ & $\begin{array}{l}0 \\
0 \\
+ \\
0 \\
0 \\
+ \\
0 \\
+ \\
0 \\
0 \\
0 \\
0 \\
0 \\
0\end{array}$ & $\begin{array}{l}0 \\
0 \\
0 \\
0 \cdot 04 \\
0 \cdot 001 \\
0 \\
0 \\
0 \\
0 \\
0 \\
0 \cdot 04 \\
0 \cdot 05 \\
0 \cdot 14 \\
0.08\end{array}$ & $\begin{array}{l}0.09 \\
0.04 \\
0.03 \\
0 \cdot 11 \\
0 \cdot 14 \\
0 \\
0 \\
0 \\
0 \cdot 19 \\
0 \cdot 28 \\
0.48 \\
0.30 \\
0.53 \\
0.41\end{array}$ & $\begin{array}{l}0 \cdot 38 \\
0 \cdot 10 \\
0 \cdot 08 \\
0 \cdot 22 \\
0 \cdot 40 \\
0 \\
0 \\
0 \\
0 \cdot 68 \\
0 \cdot 70 \\
2 \cdot 10 \\
1 \cdot 30 \\
1 \cdot 50 \\
0.68\end{array}$ & $\begin{array}{c}\bar{Z} \\
\bar{Z} \\
24 \cdot 2(\mathrm{R}) \\
\bar{Z} \\
\bar{Z} \\
\bar{Z} \\
\bar{Z} \\
59 \cdot 8(\mathrm{R}) \\
24 \cdot 8(\mathrm{R}) \\
196 \cdot 3(\mathrm{R}) \\
73 \cdot 5(\mathrm{R})\end{array}$ & $\begin{array}{c}11.6 \text { (FG) } \\
51.3 \text { (R) } \\
11.0 \text { (R) } \\
16.0 \text { (FG) } \\
60.9 \text { (FG) } \\
= \\
= \\
37.9 \text { (FG) } \\
21 . \overline{4} \text { (FG) } \\
20.7 \text { (FG) } \\
48.8 \text { (FG) } \\
18.5 \text { (FG) }\end{array}$ & 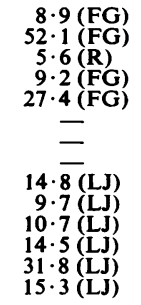 \\
\hline \multicolumn{2}{|c|}{ Normal Values } & . & . & . & . & 0.01 & 0.09 & 0.50 & $21 \cdot 4$ & $7 \cdot 2$ & $4 \cdot 2$ \\
\hline
\end{tabular}

*Saliva/plasma ${ }^{132}$ I ratios were measured in resting saliva or in salivas which had been obtained by stimulation with fruit gums and lemon juice. Because some of the patients had salivary flow ratios much below the normal range in response to these stimuli, and because saliva/plasma $182 I$ ratios are a function of salivary flow rate, it is necessary to compare ${ }^{132} I$ ratios calculated for patients with Sjögren's syndrome with the ratios obtained at equivalent flow rates in normal subjects.

For example, in Patient 2, fruit-gum stimulation produced a flow rate of $0.04 \mathrm{ml} . / \mathrm{min}$. This is below the normal range for fruit-gum stimulated salivary flow but falls in the normal range for resting flow rates. Accordingly, the ${ }^{132}$ I saliva/plasma ratio obtained after stimulation with fruit gums in this patient is to be compared with the saliva/plasma ${ }^{132}$ ratios found in resting saliva from normal patients.

The abbreviations R (resting), FG (fruit gum), and LJ (lemon juice) refer to the flow rate in which these values have to be compared agains! normal values.

Under "resting" conditions no saliva was obtained in eight patients (Table). In all but one of these patients the sialograms were abnormal. A further patient had an abnormal sialogram with a diminished flow rate (Patient 5, Table). After stimulation with fruit gums and lemon juice, the salivary flow rate was abnormally low in eight patients and all of these had abnormal sialograms. In three of these patients $(6,7$, and 8 , Table) no saliva was collected even after maximal stimulation. [In two (6 and 8) sialectasis was cavitary, and in one (7) globular]. In one patient (10) with minimal punctate sialectasis, the salivary flow rate after fruit-gum and lemonjuice stimulation lay within our normal range. All of the five patients with normal sialograms had normal salivary flow rates.

\section{(c) Measurement of Saliva/Plasma ${ }^{132}$ I Ratio}

\section{Normal Range of Saliva/Plasma ${ }^{132}$ I Ratio.-} The ratio of ${ }^{132} \mathrm{I}$ in saliva to ${ }^{132} \mathrm{I}$ in plasma is a function of the flow rate at which saliva is collected. For this reason the ratio is expressed in terms of resting, fruit-gum stimulated, and lemon-juice stimulated salivary flow rates. In 26 normal subjects the mean and standard deviation for these values were $76 \cdot 2 \pm 50 \cdot 4,17 \cdot 7 \pm 8 \cdot 8$, and $10 \cdot 9 \pm 6 \cdot 3$ respectively. When these data are plotted as a frequency distribution curve, skewness to high values is observed (not shown). The lower limit of the normal range has therefore been taken to be the lowest ${ }^{132}$ I saliva/plasma ratio obtained at each of the three individual flow rates and these values were $21 \cdot 4,7 \cdot 2$, and $4 \cdot 2$ respectively.

Patients with Sjögren's Syndrome.-The saliva/ plasma ${ }^{132}$ I ratios in those patients in whom it was possible to collect saliva are shown in the Table. In all five patients with normal sialograms, the ratios lay within the normal range. In the six patients with abnormal sialograms from whom saliva was obtained $(1,2,3,4,5$, and 9$)$, interpretation of the findings is not straightforward. Because the saliva/plasma ${ }^{132}$ I ratio is a function of salivary flow rate, reference must be made to the flow rate at which each measurement was obtained in the patients with Sjögren's syndrome (who may have diminished salivary flow rates) before comparing the ratio with values obtained in normal subjects. After each value of saliva/plasma ${ }^{132}$ I ratio in the Table, an abbreviation has been inserted in brackets showing to which flow rate it should be compared. In only one patient (3) were the saliva/plasma ${ }^{132}$ I ratios abnormal. This patient had severe cavitary changes in the glands on sialography. In the other five patients with Sjögren's syndrome and abnormal sialograms, the mean values obtained for the saliva/plasma ${ }^{132}$ I ratios were not significantly different from the findings in the normal patient. 


\section{Discussion}

In the present study, nine of the fourteen patients with Sjögren's syndrome had decreased salivary flow rates. In five, however, despite a history of xerostomia, flow rates both under "resting" conditions and after stimulation lay within our normal range. Nine of the patients had abnormal sialograms, the appearances ranging from diminished arborization of the duct system to cavitary sialectasis. The salivary flow rate was inversely related to the extent of the involvement of salivary glands as demonstrated by sialography. All the patients with abnormally low flow rates had abnoı mal sialograms. Two of three patients from whom no saliva could be collected even after maximum stimulation had the severest form of sialectasis. These findings agree with the clinical observations of Bloch and others (1965) of a correlation with the severity of xerostomia and the extent of sialectasis on sialography.

Although it is well recognized that iodide is concentrated in saliva to many times the plasma level (Honour, Myant, and Rowlands, 1952; Harden, Mason, and Buchanan, 1965; Harden, Mason, and Alexander, 1967), no studies of this trap have previously been made in patients with Sjögren's syndrome. In the present study all the patients with Sjögren's syndrome who had abnormal sialograms and from whom saliva could be obtained had normal saliva/plasma ${ }^{132} \mathrm{I}$ ratios once allowance had been made for the flow rate at which saliva was collected. The one exception to this statement was a patient (3) with very severe cavitary sialectasis in whom these ratios were abnormal. All patients with normal sialograms had normal saliva/plasma ${ }^{132}$ I ratios. It may thus be reasonably concluded that there is no abnormality of the salivary iodide trapping mechanism in patients with Sjögren's syndrome unless sialectasis be gross. One of the hopes of this study was that abnormalities of the salivary iodide concentrating mechanism might be present in patients with mild degrees of salivary gland involvement in Sjögren's syndrome who had normal or only slightly diminished salivary flow rates and normal sialograms. Our results show, however, that such is not the case.

\section{Summary}

Studies of resting parotid salivary flow rates and flow rates after salivary gland stimulation with fruit gums and lemon juice together with measurements of salivary/plasma radioiodine $\left({ }^{132} \mathrm{I}\right)$ ratios were made in fourteen patients with Sjögren's syndrome. In five of these patients, despite a history of xerostoma, salivary flow rates both under resting conditions and after stimulation lay within the normal range. An inverse correlation existed, however, between salivary flow rate and the extent of the salivary gland involvement on sialography. In only one patient (with severe cavitatory sialectasis) was an abnormally low saliva/plasma ${ }^{132} I$ ratio found. These results suggest that there is no abnormality of the salivary iodide trapping mechanism in patients with Sjögren's syndrome unless the sialectasis be gross.

\section{REFERENCES}

Alexander, W. D., Koutras, D. A., Crooks, J., Buchanan, W. W., Macdonald, E. M., Richmond, M. H., and Wayne, E. J. (1962). Quart. J. Med., 31, 281 (Quantitative studies of iodine metabolism in thyroid disease).

Bloch, K. J., Buchanan, W. W., Wohl, M. J., and Bunim, J. J. (1965). Medicine (Baltimore), 44, 187 (Sjögren's syndrome).

Carlson, A. J., and Crittenden, A. L. (1910). Amer. J. Physiol., 26, 169 (The relation of ptyalin concentration to the diet and to the rate of secretion of the saliva).

Harden, R. McG., Mason, D. K., and Alexander, W. D. (1967). Quart. J. exp. Physiol. (in press) (The salivary iodide trap: the relation between salivary iodide concentration and the plasma inorganic iodine concentration).

- - and Buchanan, W. W. (1965). J. clin. Endocr., 25, 957 (Quantitative studies of iodine excretion in saliva in euthyroid, hypothyroid, and thyrotoxic patients),

Honour, A. J., Myant, N. B., and Rowlands, E. N. (1952). Clin. Sci., 11, 447 (Secretion of radioiodine in digestive juices and milk in man).

Kerr, A. C. (1961). "The Physiological Regulation of Salivary Secretions in Man". Pergamon Press, Oxford.

Mason, D. K., Harden, R. McG., and Alexander, W. D. (1967). Brit. dent. J. (in press) (The salivary and thyroid glands: a comparative study in man). 
- — - Rowan, D., and Alexander, W. D. (1967). J. dent. Res. (in press) (Recording the pattern of salivary flow).

Park, W. M., and Mason, D. K. (1966). Radiology, 86, 116 (Hydrostatic sialography).

Ropes, M. W., Bennett, G. A., Cobb, S., Jacox, R., and Jessar, R. A. (1959). Ann. rheum. Dis., 18, 49 (1958 revision of diagnostic criteria for rheumatoid arthritis).

Sjögren, H. (1933). Acta ophthal. (Kbh.), 11, Suppl. 2 (Zur Kenntnis der Keratoconjunctivitis sicca [Keratitis filiformis bei Hypofunktion der Tränendrüsen] ).

Williamson, J., Cant, S., Mason, D. K., Greig, W. R., and Boyle, J. A. (1967). Brit. J. Ophthal., 51, (in press) (Sjögren's syndrome in thyroid disease).

Le débit salivaire et la capacité iodopexique des malades atteints de syndrome de Sjögren RÉSUMÉ

On étudia le débit salivaire de la parotide en repos et après stimulation par des pastilles et par le jus de citron et on détermina en même temps le rapport entre le taux salivaire et plasmatique de l'iode radioactif ( $\left.{ }^{132} \mathrm{I}\right) \mathrm{chez}$ quatorze malades atteints de syndrome de Sjögren. Chez cinq de ces malades, malgré des antécédents de xérostomie, le débit salivaire tant en repos qu'après stimulation se maintint dans les limites normales. On trouva toutefois un rapport inverse entre le débit salivaire et l'intensité de l'atteinte parotide à la sialographie. On n'observa que chez un malade (atteint d'une sialectase cavitaire sévère) un chiffre bas du rapport entre l'iode radioactif salivaire et plasmatique. Ces résultats suggèrent que le mécanisme iodopéxique salivaire n'est pas anormal chez des malades atteints de syndrome de Sjögren, à moins que la sialectase soit prononcée.

\section{La velocidad del flujo salival y la capacidad yodopéxica en enfermos con síndrome de Sjögren SUMARIO}

Se estudió la velocidad del flujo salival de la parótida en reposo y después de estimulación con pastillas y jugo de limón y se determinó también la razón entre las cifras salivales y plasmáticas del yodo radioactivo (132I) en catorze enfermos con sindrome de Sjögren. En cinco de ellos, no obstante una historia de xerostomía, el flujo salival tanto en reposo como después de la estimulación, se mantuvó dentro de los límites normales. Se encontró sin embargo una relación inversa entre el flujo salival y la intensidad de la afección parotídica a la sialografía. Sólo en un enfermo (con sialectasis cavitaria grave) se encontraron cifras bajas de la relación entre el yodo radioactivo salival y el plasmático. Estos resultados sugieren que el mecanismo yodopéxico salival no es anormal en enfermos con síndrome de Sjögren, a menos que la sialéctasis sea pronunciada. 